\title{
Hypoglycemia, Hypopotassemia and Hyperleukocytosis Associated with Squamous Cell Carcinoma of the Lung
}

\author{
Haruki Nakamura, MD, Takashi Imamura, MD, Nobuhiro Kimura, MD, \\ Yoshiyuki Nino, MD, Toshimitsu Okeda, MD, and Toshiyuki Yanase, MD
}

\begin{abstract}
We studied a patient with lung cancer, who exhibited severe systemic derangements of metabolism causing cachexia preceding the appearance of a large bulky tumor. The data described herein left no doubt that lung cancer growing in the patient acted as a powerful hypoglycemic factor, setting in motion widespread metabolic disorders. Inappropriate secretion of insulin may be involved in the manifestation of hypoglycemia. However, no ectopic secretion of insulin, glucagon, ACTH and aldosterone appeared to be associated with the carcinoma in the patient. From the present and previous observations, it is stressed that progressive energy loss from the patient occurs by virtue of a combination of severe anorexia and the establishment of a systemic energy-losing cycle dependent on an interplay of glycolysis in the cancer cells and stimulated gluconeogenesis in the host tissues, which in turn results in derangements of protein, lipid and electrolyte metabolism. Attemts to ameliorate the patient's distress and counterbalance the effect of the tumor by parenteral hyperalimentation were not satisfactory and resulted in only a temporary improvement. This study also demonstrated that marked granulocytosis was the result of production of an excess granulopoietic colony stimulating activity by the cancer cells.
\end{abstract}

Key Words: Lung cancer; Gachexia; Granlulopoietic colony stimulating activity; Hypoglycemia; Hyperalimentation

This paper describes a patient who had lung cancer complicated with severe muscle weakness, hypoglycemia, hypopotassemia, metabolic acidosis, hypolipidemia and marked granulocytosis unassoicated with overt infection. This case is unusual because of the severity and chronicity of the metabolic derangements which produced cachexia preceding the appearance of a large bulky tumor. The systemic effects of the lung cancer, especially the abnormal glucose metabolism, inappropriate secretion of insulin and the production of granulopoietic colony stimulating activity by the cancer cells were studied.

\section{CASE REPORT}

A 57-year-old, male office worker complained of fatigue, decreased appetite and epigastric pain of 3 months duration. $\mathrm{He}$ had suffered from right pleuritis at 6 years of age, and emphysematous bullae of the left upper lung lobe at 40 years of age, which from that time was said to have remained virtually unchanged. He was admitted to a local hospital on April 27, 1976, where a diagnosis of gastric ulcer was made. At the time, the patient presented with marked granulocytosis of unknown etiology with as many as 25,000 white cells per cubic mm. An X-ray film of the chest revealed

From the First Department of Internal Medicine, Faculty of Medicine, Kyushu University, Fukuoka 812. Received for publication May 22, 1980.

Reprint request to: Takashi Imamura, MD, The First Department of Internal Medicine, Faculty of Medicine, Kyushu University, 1-1, 3-Chome Maidashi, Higashi-Ku, Fukuoka 812, Japan. 


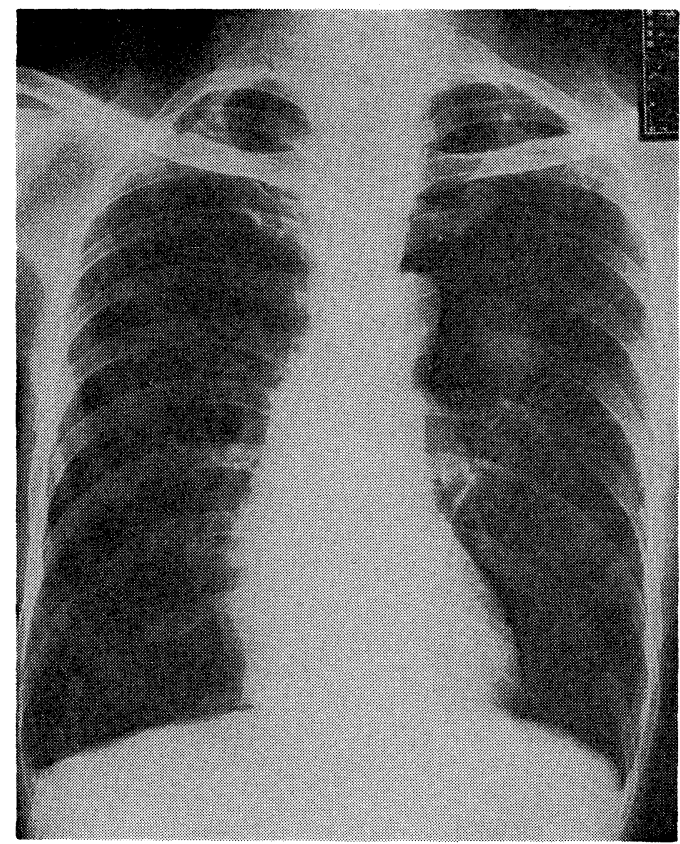

(a)

Fig. 1. X-rey films of the chest on

emphysematous bullae which occupied the entire left upper lung field. Also, a solid tumor, about $3 \mathrm{~cm}$ in diameter, was noted adjacent to the bullae in the mid left lung field (Fig la). No further investigation was performed for the lung at this time. Partial gastrectomy was carried out on May 13, 1976. No evidence of malignancy was noted on histological examination of the stomach. The leukocytosis persisted postoperatively. Following the operation, anorexia, diarrhea, clubbing of fingers, weight loss, recurrent edema of the lower extremities, and severe muscle weakness developed gradually, having progressed to the point where the patient was unable to stand up without assistance. He was admitted to Kyushu University Hospital on May 15, 1977.

The patient appeared to be emaciated, being $152 \mathrm{~cm}$ in height and $31.4 \mathrm{~kg}$ in weight. The subcutaneous adipose tissues were atrophic. No enlarged lymph nodes were palpable. The pulse was regular at 58 per minute, and the blood pressure $112-62 \mathrm{mmHg}$. No breathing sounds were audible over the left lung area. Heart sounds were normal.

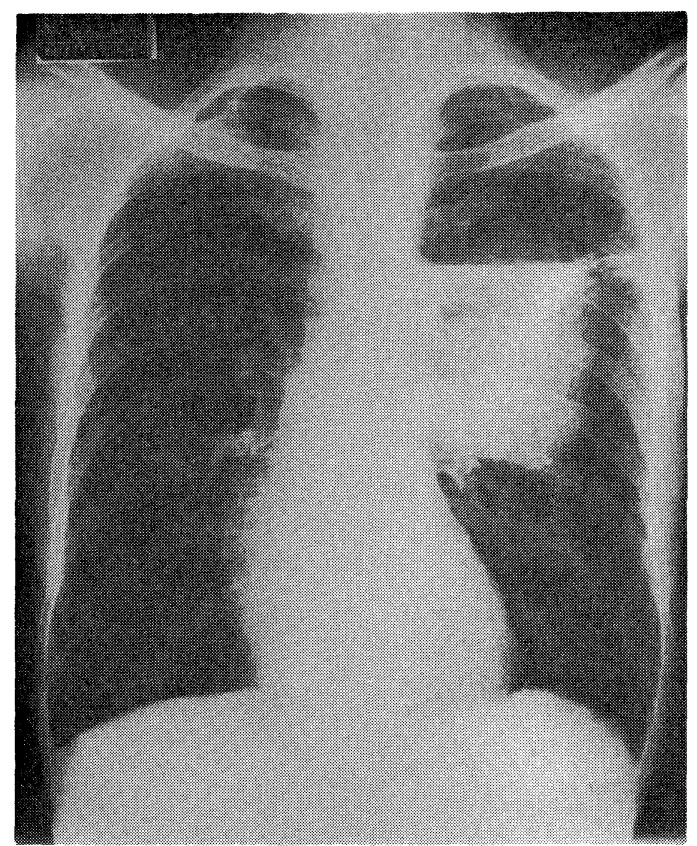

(b)

(a) May 22, 1976, and (b) April 19, 1977.

The abdomen was flat, there being neither tenderness nor tumors. The liver with normal consistency was palpable $1 \mathrm{~cm}$ below the costal margin. Generalized muscular atrophy and asthenia were notable, grasping power being nearly zero for both hands. Neurological tests were normal, except that the patient was mentally hypomanic and complained of insomnia. Both legs exhibited a moderate degree of edema. Laboratory data are shown in Table 1. Examination of the peripheral blood revealed a moderate degree of anemia and marked granulocytosis, 78,000 white cells per cubic mm consisting of $90 \%$ mature neutrophils. Bone marrow was hypercellular and hypergranulopoietic, the $\mathrm{M}$ : E ratio being 4.3: 1 without any sign of leukemia. Blood chemistry revealed fasting hypoglycemia, hypopotassemia, metabolic acidosis, hypoalbuminemia and hypolipidemia. The mean value of fasting blood glucose levels for 5 consecutive days was $29 \mathrm{mg} / 100 \mathrm{ml}$. Results of glucose torelance test and insulin and glucagon determinations are shown in Fig 2. Urinary excretion of 17-KS and 17-OHCS were 5.9 
Table 1. Laboratory Data.

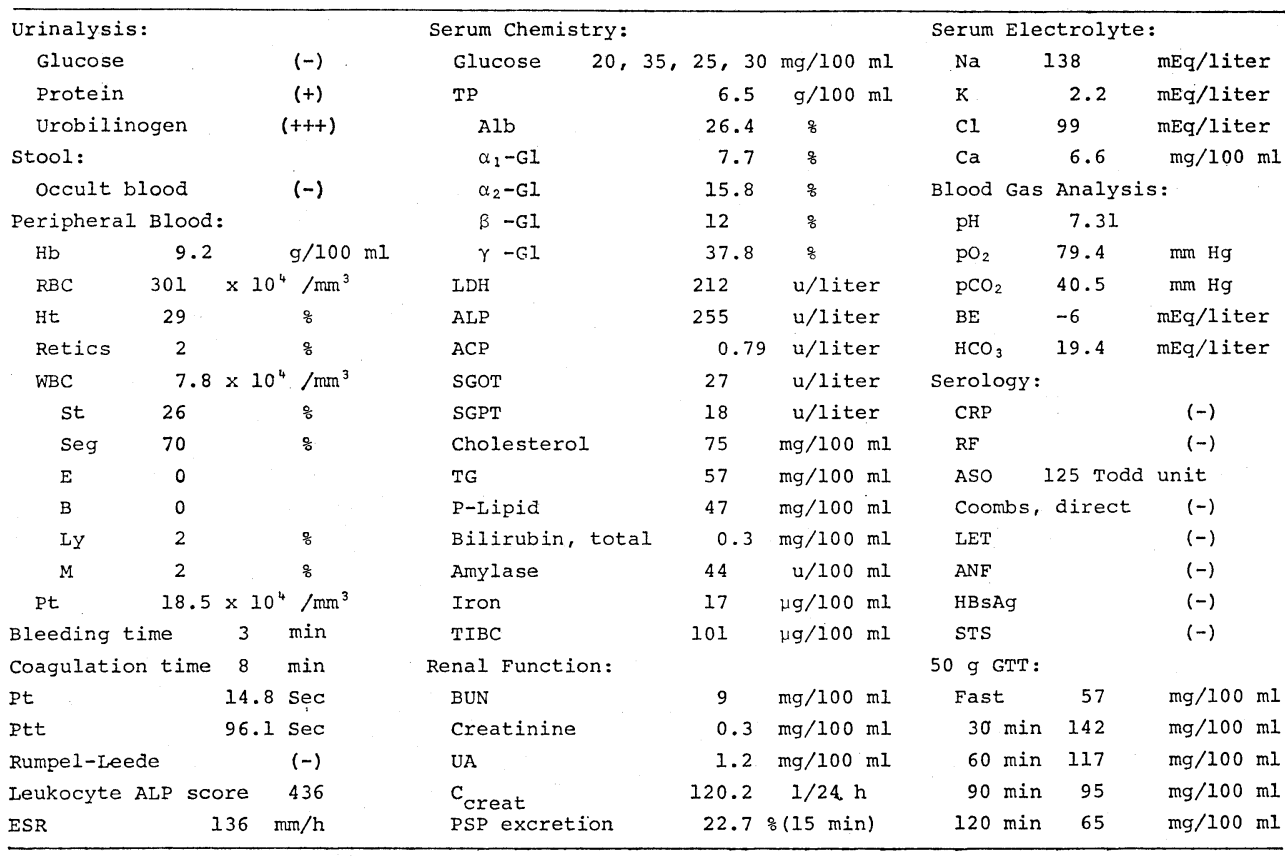
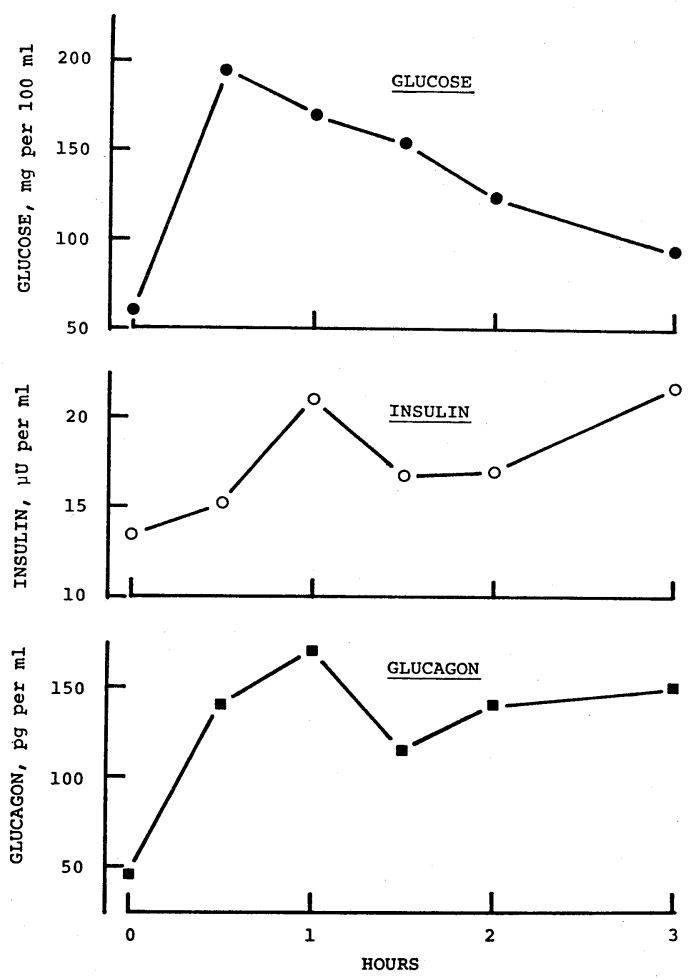

Fig. 2. The eff ect of $50 \mathrm{~g}$ glucose ingestion on plasma glucose, insulin (IRI) and glucagon. Note the poor insulin rise and inappropriate glucagon response in the patient.
$8.4 \mathrm{mg} /$ day and $3.5-12.4 \mathrm{mg} /$ day, respectively. Plasma ACTH level at 9 a.m. was 106 $\mathrm{pg} / \mathrm{ml}$ and aldosterone less than $20 \mathrm{pg} / \mathrm{ml}$ to be only slightly above or within normal range, respectively. Progressive enlargement of the lung tumor was evidenced roentgenologically (Fig 1b). From cytological examinations of the thoracentesis and closed needle biopsy of the tumor a diagnosis of squamous cell carcinoma of the left lung was made. Severe uncontrolled malabsorption states with undernutrition were thought to be related to the systemic effects of lung cancer. Marked deteriolation of the patient's condition did not permit radical therapy.

The pleural effusion and serum specimens were tested for granulopoietic colony stimulating activity (CSA) using semi-solid culture system as described in detail elsewhere ${ }^{122)}$. Briefly, neoplastic cells were aseptically collected by needle biopsy, washed with $\alpha$-MEM containing 20\% fetal bovine serum, and transplanted into the hypodermis on the back of an immunologically incompetent nude mouse. After a month, solid tumor developed, which was resected, minced 
to $3 \times 3 \mathrm{~mm}$ pieces and retransplanted to 3 other nude mice. The developement of tumors in these recipient animals was associated with marked granulocytosis, white cells being as many as 90,000 per $\mathrm{cmm}$ just as seen in the donor. The neoplastic tissues that were histologically identical with those of the original lung cancer were then transferred to the in vitro culture system, where a cell line which was designated as KSNY was established ${ }^{2}$. The clone of cells were tested for their ability to produce CSA by the method previously described ${ }^{1)}$.

Initial experiments were unsuccessful in demonstrating CSA in the patient's serum and pleural effusion, and hence the lung cancer was thought to be nonfunctional in producing CSA notwithstnding the marked granulocytosis shown in the patient ${ }^{3)}$. In subsequent studies, however, the established KSNY cell line excreted markedly increased levels of CSA into the medium ${ }^{2}$. The conditioned medium prepared from the KSNY cell line induced colony growth derived from granulopoietic colony forming unit in culture (CFU-G) at the rate of mean $81.2 \pm 4$ (SD) colonies per $2 \times 10^{5}$ human bone marrow cells, or mean $69.5 \pm 6.5$ (SD) colonies per $5 \times 10^{4}$ mouse bone marrow cells, when $20 \%$ of the conditioned medium was added to the $\alpha$-MEM supplemented with $0.88 \%$ methylcellulose and $20 \%$ fetal bovine serum. Thus, the KSNY conditioned medium had CSA activity as effective as the standard human leukocytes' conditioned medium that induced GFU-C derived colonies at the rate of mean $61.3 \pm 2(\mathrm{SD})$ colonies per $2 \times 10^{5}$ human bone marrow cells. Without these conditioned media less than 5 colonies were observed to form. Apparent inactivity initially shown with serum or pleural effusion from the patient may be explained by the concomittant presence of an inhibitory factor against CSA in the tested specimens, which remains to be confirmed. Neither immunoreactive insulin nor nonsuppressible insulin-like activities (NSILA-s) was demonstrated in the $\mathrm{KSNY}$ conditioned medium as compared to those in the conditioned media prepared from other cell lines.

In an attempt to ameliorate both recurrent hypoglycemic attacks and the signs of cachexia, as much as $150 \mathrm{~g} /$ day of glucose and electrolytes including from 40 to 90 $\mathrm{mEq}$ of potassium were administered by conventiontional intravenous infusion for two weeks. As a result of this therapy, metabolic acidosis was corrected. However, extra carbohydrate supply was still insufficient to prevent hypoglycemic attacks on fasting. During the period of these additional feeding, diet uptake ranged grom 250 $\mathrm{kcal}$ to $900 \mathrm{kcal}$ of carbohydrate per day. Serum pottasium levels were between 2.4 $\mathrm{mEq} / 1$ and $4 \mathrm{mEq} / 1$. Subsequently, the intravenous hyperalimentation by way of an indwelling central venous catheter was administered according to the guidelines for total parenteral nutrition described by Shils ${ }^{4}$. A basic formula was employed for a month, which provided about $2,150 \mathrm{kcal} /$ day with amino acids, vitamins and minerals in a volume of $3,000 \mathrm{ml}$, resulting in some transient improvement of the nutritional status. Two months after admission, the patient died of severe cachexia and late complications of cardiac failure and hepatic insufficiency. Autopsy (Kyushu University No. 17906) confirmed the presence of a poorly differentiated squamous cell carcinoma which occupied the entire left upper lung, infiltrating the adjacent pleural cavity. The tumor was about $800 \mathrm{~g}$ in weight. There was no metastasis in the vital organs distant from the lung. Hepatic cell necrosis and bile stasis were noted. The mechnaism for the production of hepatic injury was unclear. Negative results with the test for $\mathrm{HBsAg}$ and opportunities for the patient to be exposed to several antibiotica and thiazides known to produce hepatocellular jaundice provided reasonable basis for a pathologically presumptive diagnosis of drug induced liver damage.

\section{DISCUSSION}

The patient exhibited severe manifestations of cachexia associated with lung cancer. 
One finding of considerable interest is the striking systemic effects of the lung cancer preceding the appearance of a large bulky tumor. This suggests a specific mechanism apparently peculiar to the cancerous condition by which body debilitation can proceed. Although previous gastrectomy is important in causing severe anorexia, malnutrition and hypoglycemia, other factors might come into play $^{5 / 6) 7)}$.

In producing hypoglycemia both underproduction and overutilization of glucose may be operative in this patient. The causes of inadequate production of glucose during fasting can be the inadequate substrate supply. The production of glucose by the liver initailly involves the breakdown of stored glycogen and subsequently depends on gluconeogenesis, the synthesis of glucose from the precursors delivered to the liver from peripheral tissues. A period of fasting as a result of anorexia and malnutrition in this patient would be sufficient to deplete liver glycogen stores. In this circumstance hepatic glucose production must be dependent on gluconeogensis. Furthermore, since more than $200 \mathrm{~g}$ of intravenous glucose supply is required to prevent hypoglycemia in a 24-hour-period, overutilization of glucose is considerable ${ }^{8)}$. Hypoglycemia in the context of glucose overutilization and appropriately low insulin concentration occurs in association with either solid extrapancreatic tumors, usually of large size, or situations in which free fatty acids are not available for energy source in patients with severe anorexia and malnutrition.

Metabolic acidosis seen in this patient was characterized by an increased unmeasured anion acidosis which is defined as the difference between the serum sodium and the sum of the serum chloride plus bicarbonate $^{9)}$. The calculated anion gap in this patient is $19.6 \mathrm{mEq} / 1$, while the value is normally less than $13 \mathrm{mEq} / 1$. In the absence of renal azotemia, ketoacidosis or a history of ingestion of toxins and alcohols, an increased unmeasured anion acidosis is virtually always secondary to increased lactic acid production $^{910)}$. Cancer, in general, tends to utilize anywhere from 5 to 10 times as much glucose as normal tissues, which has been amply confirmed both by clinical observations and by diverse experimental sources ${ }^{7)}$ 11)1213). Glycolysis has a unique metabolic endopoint, lactic acid, which occupies a fundamental position in gluconeogenesis ${ }^{914)}$. This recycling of lactic acid assumes increased significance in causing cancer cachexia. An increased white cell mass in this patient might be contributing additively to the excessive production of lactate as described rarely in leukemia ${ }^{9)}$. In the anaerobic breakdown of glucose to lactic acid, a net 2 ATP molecules per glucose molecule is yielded to the tumor, but synthesis of glucose from the resulting lactic acid via gluconeogenesis requires the utilization of at least 6 ATP molecules derived from normal host sources ${ }^{14)}$. This systemic metabolic circuit which is characterized by the tumor's utilization of relatively large amounts of energy from the host may be the principal cause of cancer cachexia ${ }^{13)}$. Thus, one has to supplement the patient's metabolic intake, so that he will not need to mobilize his compensatory mechanisms for maintaining the normal glucose level at the expense of breakdown of the body protein and lipids. In this connection, hyperalimentation was utilized in an attempt to break the anorexia-malnutrition-cachexia cycle. However, questions still remain about the effect of long term nutrient supplementation on the sparing of the host tissues. There is definitely much to be learned about alleviating the distress of the terminal cancer patient for whom radical therapy is no longer possible.

Significant insulin concentration above 5 to $6 \mu \mathrm{U} / \mathrm{ml}$ should be considered suspicious of ectopic insulin secretion if the plasma glucose is below $50 \mathrm{mg} / 100 \mathrm{ml}$ in men, or $40 \mathrm{mg} / 100 \mathrm{ml}$ in women ${ }^{15)}$. Unfortunately, the IRI in the states where blood glucose was below $50 \mathrm{mg} / 100 \mathrm{ml}$ was not measured. From data shown in Fig 3, it is evident that the simultaneous unstimulated glucose (58 
$\mathrm{mg} / 100 \mathrm{ml})$ and IRI $(13.4 \mu \mathrm{U} / \mathrm{ml})$ fall into the normal fasting atate range if the crite$\mathrm{ria}^{15) 16)}, \quad \mathrm{IRI} / \mathrm{G}=0.23$ (noninsulinoma $<0.3<$ insulinoma), is used. The cancer cell line established from this patient secretes no measurable IRI activity into the culture medium. Therefore, tumor sponging of eutopic pancreatic hormone may be responsible for apparently inappropriate secretion of insulin from the poncreas ${ }^{17)}$. Mygyesi et $\mathrm{al}^{18)}$ reported that elevated NSILA-s was detected by radioreceptor assay in five of seven patients with cancer and hypoglycemia. However, no ectopic secretion of NSILA-s ${ }^{19)}$ seems to be the cause of hypoglycemia in this patient. Also, an association of hypokalemia with watery diarrhea and metabolic acidosis is most likely secondary to malnutrition and cancer cachexia. Ectopic secretion of gastrointestinal hormones ${ }^{8)}$ remains to be clear.

The present study clearly indicates that hypergranulocytosis is the result of production of CSA by the cancer cells. Of particular interest is the high incidence of unusual granulocytosis in pulmonary neoplasms noted here and previously by others ${ }^{2021)}$. An excess CSA produced by tomor tissues has been demonstrated to be the cause of hypergranulocytosis in patients with lung cancer ${ }^{22) 23}$ and in one with cancer of oral cavity $^{24)}$. The nature of CSA secreted by KSNY cells from this patient is different from those of KONT cell line described previously $^{23)}$ in that CSA from the KSNY cell line is equally active for the human and for the mouse bone marrow cells, while the KONT cell line is producing CSA twice as much active for human as for mouse cells. Human leukocytes' condioned media have no CSA activity for mouse marrow cells. In any event, pursuing this line of investigation should give wider and deeper knowledge of the cellular source of various factors that produce systemic effects of neoplasms, which then may provide better means in the approach to treatment.
ACKNOWLEGEMENTS: We thank Prof. H. Ibayashi and members of the Third Department of Medicine, Kyushu University, for measurements of ACTH, aldosterone and NSILA-s, Dr. Y. Nagabuchi, the Second Department of Patho$\log y$, for unpublished autopsy data, and Dr. H.B. Hamilton, Radiation Effects Research Foundation, Hiroshima, for valuable aid in the preparation of the manuscript.

\section{REFERENCES}

1) Iscove NN, Senn JS, Till JE, et al: Colony formation by normal and leukemic human marrow cells in culture: effect of conditioned medium from human leukocytes. Blood 37 : 1,1971 .

2) Kimura N, Shibuya $T$, Niho $Y$, et al: Human lung cancer cell line (KSNY) producing colony-stimulating activity which affects both human and mouse marrow cells. Gann 70 : 807, 1979.

3) Niho $Y$, Kimura N, Shibuya $\mathrm{T}$, et al: Abstract. J Kyushu Haemat Soc 26: 54, 1978.

4) Shils ME: Guidelines for total parenteral nutrition. JAMA 220: 1721, 1972.

5) Theologides A: The anorexia-cachexia syndrome: a new hypothesis. Anns NY Acad Sci $230: 14,1974$.

6) Shapot VS: Some biochemical aspects of the relationship between the tumor and the host. Advances in Cancer Res 15: 253, 1972.

7) Waterhouse G: How tumors affect host metabolism. Anns NY Acad Sci 230: 86, 1974.

8) Foster D, Rubenstein AH: Hypoglycemia, insulinoma, and other hormone-secreting tumors of the pancreas. Principles of Internal Medicine, 9th ed., Isselbacher $\mathrm{K}$, Adams RD, Braunwald E, et al. eds., McGraw-Hill Book Comp., New York, 1980, p 1758.

9) Block J : Lactic acidosis in malignancy and observations on its possible pathogenesis. Anns NY Acad Sci 230: 94, 1974.

10) Fichman M, Bethune J : Effects of neoplasms on renal elecrolyte function. Anns NY Acad Sci 230 : 448, 1974.

11) Reichard GA Jr, Moury NG Jr, Hochella NJ, et al: Quantitative estimates of the Cori cycle in the human. J Biol Chem 238: 495, 1963.

12) Gold J : Metabolic profiles in human tumors. Can Res $26:$ 695, 1966.

13) Gold J : Cancer cachexia and gluconeogenesis Anns NY Acad Sci 230: 103, 1974. 
14) Lehninger AL: Organ interrelationships in the metabolism of mammals, chap 30 . Biochemistry, 2nd ed., Lehniger AL, Worth Publishers, Inc, New York, 1975, p. 829.

15) Service FJ, Dale AJ, Elveback LR, et al: Insulinoma, clinical and diagnostic features of 60 consecutive cases. Mayo Clinic Proc 51 : 417, 1976.

16) Marimee TJ, Tyson EJ, Florida G: Hypoglycemia in man, pathologic and physiologic variants. Diabetes 26: 161, 1977.

17) Unger $\mathrm{RH}$, Lochmer $\mathrm{J} \mathrm{deV}$, Eisentraut AM : Identification of insulin and glucagon in a bronchogenic metastasis. J Clin Endocrinol Metab 24 : 823, 1964.

18) Megyesi K, Kahn GR, Rosse J, et al : Hypoglycemia in association with extrapancreatic tumors: demonstration of elevated plasma NSILA-s by a new radioreceptor assay. J Glin Endocrinol Metab 38: 931, 1974.

19) Odell WD, Wolfson AR: Humoral syndromes associated with cancer. Anns Rev Med 29 379, 1978.

20) Robinson WA: Granulocytosis in neoplasia. Anns NY Acad Sci 230: 212, 1974.

21) Fahey RJ: Unusual leukocyte response in primary carcinoma of the lung. Cancer 4: 930, 1951.

22) Asano S, Urabe A, Okabe T, et al: Demonstration of granulopoietic factors in the plasma of nude mice transplanted with a human lung cancer and in tumor tissue. Blood 49: 845, 1977.

23) Kimura N, Niho $Y$, Ono J, et al: An established lung cancer cell line producing colony. stimulating activity. Proc Jap Acad Sci 54 : 548, 1978.

24) Sato N, Asano S, Ueyama, et al: Granulocytosis and colony-stimulating activity (CSA) produced by a human squamous cell carcinoma. Cancer $43:$ 655, 1979. 